\title{
Improved Outcomes in Diabetes Care for Rural African Americans
}

Paul Bray, MA, LMFT'

Doyle M. Cummings, PbarmD, FCP, FCCP ${ }^{2,3}$

Susan Morrissey, $M A^{2}$

Debra Thompson, DNP, RN, CDE

Don Holbert, $\mathrm{PbD}{ }^{4}$

Kyle Wilson, BS

Eric Lukosius, BS

Robert Tanenberg, $M D^{3,5}$

'Vidant Health (formerly University Health System), Greenville, North Carolina

${ }^{2}$ Department of Family Medicine, Brody School of Medicine, East Carolina University, Greenville, North Carolina

${ }^{3}$ ECU Diabetes and Obesity Institute, and Center for Health Disparities Research, East Carolina University, Greenville, North Carolina

${ }^{4}$ Department of Biostatistics, East Carolina University, Greenville, North Carolina

${ }^{5}$ Department of Internal Medicine, East Carolina University, Greenville, North Carolina

Conflicts of interest: authors report none.

\section{CORRESPONDING AUTHOR}

Paul Bray, MA, LMFT

Vidant Health, Vidant Medical Group

2100 Stantonsburg Rd

Greenville, NC 27834

pbray@vidanthealth.com

\begin{abstract}
PURPOSE Rural low-income African American patients with diabetes have traditionally poorer clinical outcomes and limited access to state-of-the-art diabetes care. We determined the effectiveness of a redesigned primary care model on patients' glycemic, blood pressure, and lipid level control.
\end{abstract}

METHODS In 3 purposively selected, rural, fee-for-service, primary care practices, African American patients with type 2 diabetes received point-of-care education, coaching, and medication intensification from a diabetes care management team made up of a nurse, pharmacist, and dietitian. In 5 randomly selected control practices matched for practice and patient characteristics, African American patients received usual care. Using univariate and multivariate adjusted models, we evaluated the effects of the intervention on intermediate (median 18 months) and long-term (median 36 months) changes in glycated hemoglobin (hemoglobin $A_{1 c}$ ) levels, blood pressure, and lipid levels, as well as the proportion of patients meeting target values.

RESULTS Among 727 randomly selected rural African American diabetic patients (368 intervention, 359 control), intervention patients had a significantly greater reduction in mean hemoglobin $A_{1 c}$ levels at intermediate $(-0.5 \%$ vs $-0.2 \%$; $P$ $<.05)$ and long-term $(-0.5 \%$ vs $-0.10 \% ; P<.005)$ follow-up in univariate and multivariate models. The proportion of patients achieving a hemoglobin $A_{1 c}$ level of less than $7.5 \%(68 \%$ vs $59 \%, P<.01)$ and/or a systolic blood pressure of less than $140 \mathrm{~mm} \mathrm{Hg}(69 \%$ vs $57 \%, P<.01)$ was also significantly greater in intervention practices in multivariate models.

CONCLUSION Redesigning care strategies in rural fee-for-service primary care practices for African American patients with established diabetes results in significantly improved glycemic control relative to usual care.

Ann Fam Med 2013;11:145-150. doi:10.1370/afm.1470.

\section{INTRODUCTION}

$\mathrm{D}$ ata from the United Kingdom Prospective Diabetes Study (UKPDS) study has shown that improving glycemic and blood pressure control in patients with diabetes results in significant reductions in morbidity and mortality. ${ }^{1}$ Many patients, particularly rural minority patients, however, do not achieve these recommended levels of care. Dansky et $\mathrm{al}^{2}$ found that rural Medicare beneficiaries with diabetes mellitus reported fewer physician visits than urban patients, whereas others have shown that low-income, rural patients with diabetes are more likely to receive care from a primary care physician than from a specialist. ${ }^{3,4}$ In studies in the United States ${ }^{3,5,6}$ and Canada, ${ }^{7}$ diabetes care in rural areas has been found to be inadequate relative to the standards described by the American Diabetes Association (ADA) and often is of lower quality than in urban settings. In a study by Coon et $\mathrm{al}_{1}{ }^{8}$ as well as in studies of rural populations by Porterfield and Kinsinger ${ }^{9}$ and Bell et al ${ }_{1}^{10}$ hyperglycemia was also less well controlled. Moreover, in unpublished data from 233 diabetic patients from the rural region of this study, African Americans were 1.7 
times more likely than whites to have hemoglobin $\mathrm{A}_{1 \mathrm{c}}$ levels greater than $8.0 \%$, even when controlling for age, education level, body mass index, and health insurance. These outcomes are confounded by poverty, which is also associated with patients not reaching goals. ${ }^{11}$

Numerous interventions have been explored that address the challenges of inadequate control. In a Cochrane Collaboration systematic review of 41 studies involving 48,000 patients, the authors describe the effectiveness of health professionals-directed interventions, organizational change interventions, and patient-focused interventions. ${ }^{12}$ In a recent assessment of system redesign using the Chronic Care Model, ${ }_{1}^{13}$ patients' hemoglobin $A_{1 c}$ levels decreased significantly with a redesigned practice but not in the usual care settings. Most studies, however, have occurred in urban prepaid or managed care settings involving mostly white patients. The system redesign techniques recommended in the Chronic Care Model for adoption in primary care ${ }^{14}$ have had limited evaluation in rural, feefor-service, primary care practices that have substantial minority and low-income populations. ${ }^{15}$ Finally, most studies have examined only short-term outcomes, and more research on long-term outcomes is needed. We therefore implemented in fee-for-service, primary care practices a model of redesigned care that offered interprofessional care management for African American patients with type 2 diabetes to determine its effectiveness on their intermediate- and long-term glycemic, blood pressure, and lipid levels compared with patients receiving usual care in similar control practices.

\section{METHODS}

This quasi-experimental study assessed the effectiveness of a primary care practice redesign that included a care management intervention, piloted by the investigators ${ }_{1}^{16}$ similar to the health-coaching requirements described for patient-centered medical homes. ${ }^{17}$ There are 6 key elements to the intervention design: education with behavioral coaching, treatment intensification, point-of-care management, expanded roles of clinic staff to facilitate management, a teamcare approach, and physician leadership. Full details regarding the program's design, including a detailed description of clinic staff and leadership training, patient flow protocols, implementation details, start-up budgets, staff roles, and education protocols can be found at http://www.ecarediabetes.org/, the ECAREDIABETES Web site.

All study practices were located in rural counties as defined by the US Census Bureau (ie, non-metropolitan statistical areas and with a population density of less than 1,000 persons per square mile). For the intervention group, we purposively selected 3 rural, fee-for-service, primary care practices in which African Americans have traditionally poor clinical outcome as described above. All African American adult patients with type 2 diabetes received point-of-care diabetes care management involving education, self-management coaching, and medication adjustment from a team made up of a nurse case manager, pharmacist, and dietitian. The intervention clinics were purposefully selected because of local funding requirements and staff willingness to participate in diabetes quality improvement training and because senior leadership committed time and resources to improve clinical outcomes.

A nurse, pharmacist, and dietitian care manager traveled to the 3 different intervention practice sites on different days and provided proactive, individualized, office-based care management and follow-up as part of the usual office visit for adult patients with type 2 diabetes mellitus. Patients with new-onset type 2 diabetes mellitus or who had a hemoglobin $\mathrm{A}_{1 \mathrm{c}}$ level of greater than $7.5 \%$ were scheduled to be seen by one of the care managers. The clinical targets in the intervention practices included reducing elevated hemoglobin $\mathrm{A}_{1 \mathrm{c}}$ levels to $7.5 \%$, blood pressure to less than 140/90 $\mathrm{mm} \mathrm{Hg}$, and low-density lipoprotein (LDL) cholesterol levels to less than $100 \mathrm{mg} / \mathrm{dL}$. These pragmatic targets were selected because many of these patients were older, had multiple comorbidities, and had a long duration of diabetes, and because data have shown that African American patients have higher hemoglobin $\mathrm{A}_{1 \mathrm{c}}$ values than white populations. ${ }^{18,19}$

The redesign model encouraged that diabetic patients in intervention practices be scheduled on specific days when the additional care manager was in the practice. Each patient was seen on average 4 times over a 12 -month period by the nurse, pharmacist, or dietitian care manager for 30 to 60 minutes as part of and in addition to the traditional physician visit (ie, point of care). Subsequently the patient was seen every 3 to 6 months by the care manager as part of the physician visit for an additional 2 years. During these visits the care managers used a behaviorally centered coaching strategy that was tailored to overcome psychosocial and environmental barriers to behavioral change through a strong, culturally relevant focus on emotional, cultural, and social factors related to eating, activity, and medications. When a patient's hemoglobin $\mathrm{A}_{1 \mathrm{c}}$ level was above $7.5 \%$, the pharmacist and nurse care managers, in collaboration with the primary care physician, increased the patient's medication regimen, including the dosage of current medications and the initiation of new oral medications or insulin.

A comparison group of patients was made up of African American adults with type 2 diabetes receiving 
usual care from their regular physicians in 5 rural control practices. The practices were selected by stratified randomization (ie, stratified by practice financing to match the rural health clinic and community health center funding status in the intervention practices) from a sampling frame of similar regional practices (eg, similar practice financing and payer mix) and patient characteristics (eg, race, age). Usual care provided in the control clinics was a billable clinic visit to a physician, nurse practitioner, or physician assistant, but these clinicians did not provide point-of-care selfmanagement coaching or a health coach-educator, and there was no team-based medication adjustment. Usual care visits lasted an average of 15 minutes and included standard measurement of hemoglobin $\mathrm{A}_{1 \mathrm{c}}$ levels, blood pressure, and lipid levels. Medications including insulin were prescribed and adjusted based on the sole clinical judgment of the physician. Diabetes educational handouts were frequently offered. In 2 control practice communities, a health educator was available at local health departments through referral.

To assess the impact of the intervention or usual care in each of the 8 practices, a biostatistician, using a review of billing and electronic health records, assigned a unique numerical identifier to African American patients with type 2 diabetes, and a sample of patients was obtained using a computer-based random number generator. The following patient data were then collected by unblinded staff at baseline, 18 months (intermediate), and 36 months (long term): demographic characteristics (age, sex, insurance, duration of diabetes), height, weight, and blood pressure using standard procedures; and blood specimens obtained by venipuncture and measured in the hospital laboratory using standard laboratory procedures for total, LDL, and high-density lipoprotein (HDL) cholesterol, and glycemic control (hemoglobin $\mathrm{A}_{1 \mathrm{c}}$ ). The study was approved by the institutional review board, and each patient provided informed consent.

Descriptive statistics (means and $t$ tests for continuous variables; proportions and $\chi^{2}$ statistics for categorical variables) were used to characterize the study patients' demographic characteristics and diabetes-specific outcome measures at baseline. The study design used an intention-to-treat analysis; for patients who did not complete the study in both arms, the investigators carried the last observation forward for data analysis. Using baseline, 18-month (intermediate), and 36-month (long-term) follow-up values, we calculated the mean change in hemoglobin $\mathrm{A}_{1 \mathrm{c}}$ levels; systolic blood pressure; and total, LDL, and HDL cholesterol levels. Intervention and control outcome means were compared in univariate analyses using independent samples $t$ tests. We also calculated the number and percentage of patients who met target goals (defined above) at baseline and at the intermediate and final evaluations, each of which were compared by $\chi^{2}$ analysis.

The data for hemoglobin $A_{1 c}$ levels were further analyzed using a linear mixed-modeling strategy to examine the overall impact of the composite intervention on change in hemoglobin $\mathrm{A}_{1 \mathrm{c}}$ levels in intervention practice patients relative to that in control practice patients using baseline values as a covariate. Specifically, these linear mixed models were constructed to assess the multivariate relationship between the continuous dependent variable (eg, change in hemoglobin $\mathrm{A}_{1 \mathrm{c}}$ level) and a variety of continuous and categorical variables, including age, sex, duration of diabetes, health insurance, practice attended (intervention vs control practice), and number of office visits in the last year. Likewise, the data on the proportion of patients achieving target values (eg, hemoglobin $\mathrm{A}_{1 \mathrm{c}}$ level of less than $7.5 \%$ ) in intervention and control practices were analyzed using multivariable logistic regression that incorporated the same additional variables. All fitted models included correlation structures to accommodate clustering of patients in practices, and appropriateness of models was examined using residual analysis and model diagnostics. All analyses were performed using SAS 9 (SAS Institute).

Finally, although a full economic analysis is beyond the scope of this article, we briefly present a summary of total and per-patient program costs (primarily personnel costs for year 1 start-up and year 2 and 3 ) in comparison with the total 3-year patient panel served. A fuller description of costs and revenue, as well as potential business plans, are presented on the ECAREDIABETES Web site (http://www.ecarediabetes.org).

\section{RESULTS}

\section{Patients}

Seven hundred twenty-seven randomly selected African American patients with established type 2 diabetes mellitus signed a statement of informed consent and were enrolled in this study, including 368 intervention practice patients, and 359 control practice patients Approximately $5 \%$ of patients approached declined to participate in the study. A total of 25 patients in the intervention practices and 26 patients in the control practices did not complete the study. Dropouts were primarily due to patients moving from the area.

There were no statistically significant differences between patients in the intervention and control practices in demographic characteristics or in mean clinical parameters at baseline. The mean age was 59.5 years ( $\mathrm{SD}=12.0$ years) for intervention and 60.6 years $(\mathrm{SD}=12.4$ years $)$ for control patients, $66 \%$ of the inter- 


\begin{tabular}{|c|c|c|c|c|c|c|}
\hline \multirow[b]{2}{*}{ Clinical Parameters } & \multicolumn{3}{|c|}{ Control Practice ( $n=359$ Patients) } & \multicolumn{3}{|c|}{ Intervention Practice ( $n=368$ Patients) } \\
\hline & Baseline & $18 \mathrm{Mo}$ & $36 \mathrm{Mo}$ & Baseline & $18 \mathrm{Mo}$ & 36 Mo \\
\hline $\mathrm{HbA}_{1 c}$, mean (SD), \% & $7.9(2.2)$ & $7.7(1.9)$ & $7.8(2.0)$ & $7.9(2.1)$ & $7.4(1.6)^{\mathrm{a}}$ & $7.4(1.9)^{b}$ \\
\hline$\leq 7.5 \%$, No. (\%) & $134(56)$ & $170(60)$ & $165(59)$ & $164(55)$ & $189(66)$ & $146(68)^{c}$ \\
\hline$>7.5 \%$, No. $(\%)$ & $106(44)$ & $114(40)$ & $117(41)$ & $132(45)$ & $96(34)$ & $69(32)^{c}$ \\
\hline $\begin{array}{l}\text { Systolic/diastolic blood pressure, mean } \\
\text { (SD), mm Hg }\end{array}$ & $\begin{array}{c}138(18) / \\
81(10)\end{array}$ & $\begin{array}{l}139(16) / \\
80(9)\end{array}$ & $\begin{array}{c}140(17) / \\
79(10)\end{array}$ & $\begin{array}{l}135(16) / \\
79(8)\end{array}$ & $\begin{array}{l}135(14) / \\
78(9)\end{array}$ & $\begin{array}{l}135(16) / \\
78(9)\end{array}$ \\
\hline$\leq 40 \mathrm{~mm} \mathrm{Hg}$, No. (\%) & $208(64)$ & $198(59)$ & $178(57)$ & $257(71)$ & $222(69)^{c}$ & $171(69)^{c}$ \\
\hline$>140 \mathrm{~mm} \mathrm{Hg}$, No. (\%) & $116(36)$ & $140(41)$ & $134(43)$ & $107(29)$ & $101(31)^{c}$ & $76(31)^{c}$ \\
\hline LDL cholesterol, mean (SD), mg/dL & $101(36)$ & $99(38)$ & $97(32)$ & $105(33)$ & $95(32)$ & $99(36)^{a}$ \\
\hline$\leq 100$ mg/dL, No. (\%) & $64(52)$ & $141(57)$ & $136(59)$ & $94(46)$ & $128(61)$ & $91(57)$ \\
\hline$>100$ mg/dL, No. (\%) & $60(48)$ & $106(43)$ & $94(41)$ & $109(54)$ & $81(39)$ & $68(43)$ \\
\hline HDL cholesterol, mean (SD), mg/dL & $50(13.3)$ & $51(13.4)$ & $50(13.3)$ & $50(12.7)$ & $50(13.6)$ & $52(13.9)^{a}$ \\
\hline Total cholesterol, mean (SD), mg/dL & $176(39.7)$ & $177(42.5)$ & $170(38.1)$ & $182(38.1)$ & $171(37.7)$ & $176(39.1)$ \\
\hline
\end{tabular}

vention and $63 \%$ of the control patients were female, and the mean duration of diabetes for the intervention patients was 13 years $(\mathrm{SD}=6.4$ years) and for the control patients was 11 years $(\mathrm{SD}=7.2$ years). Baseline characteristics, as well as mean changes in hemoglobin $\mathrm{A}_{1 \mathrm{c}}$, blood pressure, and lipid values from baseline to intermediate (median 18 months) and to long-term follow-up (median 3.3 years) are given in Table 1. Mean values for hemoglobin $A_{1 c}$ in each group were similar at baseline and above target values recommended by the American Diabetes Association. ${ }^{20}$

\section{Clinical Outcomes}

As shown in Table 1, mean hemoglobin $\mathrm{A}_{1 \mathrm{c}}$ levels decreased significantly more from baseline to the 18 -month $(-0.5 \%$ vs $-0.2 \% ; P<.05)$ and the 36 -month follow-up $(-0.5 \%$ vs $-0.1 \%$; $P<.005)$ among intervention practice patients than among control practice patients. The mean change in LDL and HDL cholesterol values in intervention practice patients was significantly greater than in control practice patients in univariate comparisons. Improvements in the proportion of patients reaching clinical targets are also displayed in Table 1 . A significantly greater percentage of patients in the intervention practices achieved a hemoglobin $\mathrm{A}_{1 \mathrm{c}}$ value near
$7 \%$ at the final assessments $(68 \%$ vs $59 \% P<.01)$. The proportion achieving a systolic blood pressure of less than $140 \mathrm{~mm} \mathrm{Hg}$ was also substantially greater in the intervention practices at 18 and 36 months. There were no significant differences in clinical outcomes by sex.

In multivariate linear modeling, the mean decrease in hemoglobin $\mathrm{A}_{\mathrm{lc}}$ levels from baseline to final followup for intervention practice patients was significantly greater when compared with control practice patients $\left(F_{(\mathrm{v} 1, \mathrm{v} 6)}=17.97 ; P=.005\right)$, even when controlling for other variables (Table 2). Older age and higher baseline hemoglobin $\mathrm{A}_{1 \mathrm{c}}$ values were also significant independent predictors of greater long-term change in hemoglobin $\mathrm{A}_{1 \mathrm{c}}$ levels. A longer duration of diabetes was significantly and inversely related to the long-term change in hemoglobin $\mathrm{A}_{\mathrm{cc}}$ levels in the multivariate model (Table

\begin{tabular}{|c|c|c|c|c|}
\hline \multirow[b]{2}{*}{ Variable } & \multicolumn{2}{|c|}{$\begin{array}{c}\text { Multivariate Linear Model } \\
\text { Mean Change }\end{array}$} & \multicolumn{2}{|c|}{$\begin{array}{c}\text { Multivariate Logistic } \\
\text { Regression Model Change in } \\
\text { Percentage With } \mathrm{HbA}_{1 \mathrm{c}} \leq 7.5 \%\end{array}$} \\
\hline & $\begin{array}{c}\text { Model } \\
\text { Parameter (SE) }\end{array}$ & $\begin{array}{c}\text { Effect } \\
P \text { Value }\end{array}$ & OR & $95 \% \mathrm{Cl}$ \\
\hline Age & $0.022(0.006)$ & $<.001$ & 1.041 & $1.007-1.075$ \\
\hline Sex & $0.184(0.138)$ & NS & 0.804 & $0.356-1.818$ \\
\hline Duration of diabetes & $-0.026(0.010)$ & .009 & 0.998 & $0.955-1.043$ \\
\hline No. of visits per year & $0.008(0.029)$ & NS & 1.080 & $0.898-1.30$ \\
\hline Baseline $\mathrm{HbA}_{1 c}$ level & $0.606(0.030)$ & $<.001$ & 0.417 & $0.308-0.564$ \\
\hline $\begin{array}{l}\text { Intervention vs control } \\
\text { clinic effect }^{\mathrm{a}}\end{array}$ & & .005 & 0.393 & $0.156-0.988$ \\
\hline
\end{tabular}


2). There was no significant independent effect of the individual clinic within the intervention or control strata. Results of the logistic regression model examining change from baseline to final follow-up in the odds of patients meeting the target hemoglobin $\mathrm{A}_{1 \mathrm{c}}$ level $(\leq 7.5 \%)$ are also given in Table 2 . In this analysis, control practice patients were significantly less likely $(\mathrm{OR}=0.39$; 95\% CI, 0.16-0.98) to achieve the target hemoglobin $\mathrm{A}_{1 \mathrm{c}}$ levels even when controlling for other variables. As in the linear model, age and baseline hemoglobin $\mathrm{A}_{1 \mathrm{c}}$ level were also independent predictors of change in the odds of meeting the target hemoglobin $\mathrm{A}_{1 \mathrm{c}}$ level.

The cost of implementing the intervention was as follows: annual personnel costs for the 3 -year project were $\$ 86,800$ for 1 full-time equivalent registered nurse, $\$ 12,000$ for 0.1 full-time equivalent clinical pharmacist, and $\$ 43,400$ for 0.5 full-time equivalent dietitian; $\$ 5,000$ were spent on supplies and miscellaneous startup costs. The 1.6 full-time equivalent coach-educators covered an annual diabetes panel of 1,280 patients. The cost per patient per year was approximately $\$ 115$.

\section{DISCUSSION}

In a study of primary care practices based in rural communities with high rates of poverty and with highrisk African Americans who have well-established type 2 diabetes and traditionally poor outcomes, we found that redesigning diabetes care to incorporate interprofessional care management results in significantly greater intermediate and long-term improvement in glycemic control. These findings are consistent with those of Glazier et al $^{21}$ and Pimouguet et al. ${ }^{22,24}$ Reductions in hemoglobin $\mathrm{A}_{1 \mathrm{c}}$ levels were modest but approach those observed in the UKPDS study ${ }^{1}$ and suggest the potential for improved long-term microvascular and macrovascular outcomes ${ }^{2,3}$

We also observed modest improvements in the proportion of patients with a systolic blood pressure of less than $140 \mathrm{~mm} \mathrm{Hg}$ and small but significant changes in mean LDL and HDL cholesterol levels. These outcomes are similar to those of the multifactorial intervention in the Steno-2 study, which was associated with significant reductions in mortality, as well as microvascular and macrovascular outcomes. ${ }^{25}$ Further, because visit frequency was not a significant independent predictor, the improvement in clinical outcomes may be related to improvements in the intensity and quality of the visit, specifically at the point of care-which has important implications for health care reform.

This study involved only rural African American patients, a group previously shown to have important challenges in access to care and poor clinical outcomes. ${ }^{10,11}$ The busy practices serving these large patient populations represent fragile care environments, as they are often the only sources of care and have limited clinical staff. Our redesign study shows that diabetes care can be effectively managed even in environments with limited resources.

Parchman et $\mathrm{al}^{26}$ and Stange ${ }^{27}$ described how busy primary care physicians struggle with the challenge of competing demands when attempting to address elevated hemoglobin $\mathrm{A}_{\mathrm{ic}}$ levels. Our strategy suggests that a portion of chronic diabetes management can be accomplished with an interprofessional team, potentially making the clinicians more available for acute problems. Our findings should be viewed as early evidence suggesting the effectiveness of an interprofessional environment similar to a patient-centered medical home. ${ }^{17}$

In conventional care, diabetic patients are referred for a separate diabetes education visit, often located apart from the practice and often on a different day. Our findings illustrate the advantage of concurrent diabetes care management integrated into the primary care visit. Interprofessional diabetes care team management on a part-time but consistent basis appears to significantly improve long-term glycemic control and benefit blood pressure and lipid level outcomes. ${ }^{28}$ Because the interprofessional care team is shared across 3 practices, personnel costs might be allocated across multiple funding sources.

This study has several limitations. Some improved outcomes may have resulted from purposefully selecting intervention sites that required quality improvement training and a leadership commitment. These elements, however, may be a prerequisite for successful teambased care management initiatives. Further, the control sites were chosen randomly from practices with similar patient and practice characteristics and from the same regional environment, which included systemic efforts driven by national and state initiatives to improve diabetes care among federally funded centers and clinics. Other limitations are our lack of information on medication adherence or treatment intensification and patient satisfaction, and how those factors affected the intervention. In our study, we incorporated a complex, multicomponent intervention, and the study was not designed, powered, or funded to tease apart the relative contributions of various components. Even so, our findings were similar to those of other investigators who used interventions centered on care management ${ }^{22}$ and suggest that the redesign strategy is beneficial.

Although this study was not designed to include cost-effectiveness analysis, if the study results were hypothetically applied to an annual caseload of 1,280 patients for 1.6 full-time equivalent educator-coaches, the cost to reach target hemoglobin $\mathrm{A}_{1 \mathrm{c}}$ levels at 18 
months is $\$ 1,044$ per patient. These costs might be covered by a combination of insurance reimbursement and health system investment. Program costs and strategies for cost recovery are discussed on the program's Web site (http://www.ecarediabetes.org).

We present evidence of the effectiveness of a redesigned primary care delivery system with expanded care management similar to a patient-centered medical home. Although our findings illustrate important progress, more research is required to identify program modifications to facilitate more patients meeting clinical goals.

To read or post commentaries in response to this article, see it online at http://www.annfammed.org/content/11/2/145.

Key words: diabetes; improved outcomes; African Americans; delivery redesign; rural; patient-centered medical homes

Submitted March 13, 1012; submitted, revised, July 28, 2012; accepted August 21, 2012.

Financial support: Robert Wood Johnson Foundation, Kate B. Reynolds Charitable Trust, and the Roanoke Chowan Foundation.

Previous presentations: This study was presented as part of the audio poster tour at the $71^{\text {st }}$ Annual Scientific Sessions of the American Diabetes Association (Abstract \#1167-P), San Diego, California, June 23, 2011, and an abstract of the work published in the June supplement to the journal Diabetes.

Acknowledgments: We acknowledge the many contributions of the practices involved in this study.

\section{References}

1. UK Prospective Diabetes Study (UKPDS) Group. Intensive bloodglucose control with sulphonylureas or insulin compared with conventional treatment and risk of complications in patients with type 2 diabetes (UKPDS 33). Lancet. 1998;352(9131):837-853.

2. Dansky KH, Dirani R. The use of health care services by people with diabetes in rural areas. J Rural Health. 1998;14(2):129-137.

3. McCall DT, Sauaia A, Hamman RF, Reusch JE, Barton P. Are lowincome elderly patients at risk for poor diabetes care? Diabetes Care. 2004:27(5):1060-1065.

4. Woodwell DA, Cherry DK. National Ambulatory Medical Care Survey: 2002 summary. Adv Data. 2004;(346):1-44.

5. Andrus MR, Kelley KW, Murphey LM, Herndon KC. A comparison of diabetes care in rural and urban medical clinics in Alabama. J Community Health. 2004;29(1):29-44.

6. Zoorob RJ, Mainous AG III. Practice patterns of rural family physicians based on the American Diabetes Association standards of care. J Community Health. 1996;21(3):175-182.

7. Toth EL, Majumdar SR, Guirguis LM, Lewanczuk RZ, Lee TK, Johnson JA. Compliance with clinical practice guidelines for type 2 diabetes in rural patients: treatment gaps and opportunities for improvement. Pharmacotherapy. 2003;23(5):659-665.

8. Coon P, Zulkowski K. Adherence to American Diabetes Association standards of care by rural health care providers. Diabetes Care. 2002;25(12):2224-2229.

9. Porterfield DS, Kinsinger L. Quality of care for uninsured patients with diabetes in a rural area. Diabetes Care. 2002;25(2):319-323.
10. Bell RA, Camacho F, Goonan K, et al. Quality of diabetes care among low-income patients in North Carolina. Am J Prev Med. 2001;21(2):124-131.

11. Drury TF, Powell AL. Prevalence of known diabetes among black Americans. In: Harris, MI, Hammon RF, eds. Diabetes in America. Washington, DC: Department of Health \& Human Services; 1987. Pub no. (NIH) 87-1250.

12. Renders CM, Valk GD, Griffin SJ, Wagner EH, Eijk JT, Assendelft WJJ. Interventions to improve the management of diabetes mellitus in primary care, outpatient and community settings. Cochrane Database Syst Rev. 2001;(1)(Issue 4):CD001481.

13. Piatt GA, Orchard TJ, Emerson S, et al. Translating the chronic care model into the community: results from a randomized controlled trial of a multifaceted diabetes care intervention. Diabetes Care. 2006;29(4):811-817.

14. Bodenheimer T, Wagner EH, Grumbach K. Improving primary care for patients with chronic illness. JAMA. 2002;288(14):1775-1779.

15. Heisler M, Smith DM, Hayward RA, Krein SL, Kerr EA. Racial disparities in diabetes care processes, outcomes, and treatment intensity. Med Care. 2003;41(11):1221-1232.

16. Bray P, Thompson D, Wynn JD, Cummings DM, Whetstone L. Confronting disparities in diabetes care: the clinical effectiveness of redesigning care management for minority patients in rural primary care practices. J Rural Health. 2005;21(4):317-321.

17. Nutting PA, Miller $W L$, Crabtree $B F$, Jaen $C R$, Stewart EE, Stange $K C$. Initial lessons from the first national demonstration project on practice transformation to a patient-centered medical home. Ann Fam Med. 2009;7(3):254-260.

18. Herman $W H, M a Y$, Uwaifo $G$, et al; Diabetes Prevention Program Research Group. Differences in A1C by race and ethnicity among patients with impaired glucose tolerance in the Diabetes Prevention Program. Diabetes Care. 2007;30(10):2453-2457.

19. Herman WH, Dungan KM, Wolffenbuttel BHR, et al. Racial and ethnic differences in mean plasma glucose, hemoglobin $A_{1 c}$ and 1.5-anhydroglucitol in over 2000 patients with type 2 diabetes. J Clin Endocrinol Metab. 2009;94(5):1689-1694.

20. American Diabetes Association. Standards of medical care in diabetes-2011. Diabetes Care. 2011;34(Suppl 1):S11-S61.

21. Glazier RH, Bajcar J, Kennie NR, Willson K. A systematic review of interventions to improve diabetes care in socially disadvantaged populations. Diabetes Care. 2006;29(7):1675-1688.

22. Pimouguet $C$, LeGoff M, Thiebaut R, Dartigues JF, Helmer C. Effectiveness of disease-management programs for improving diabetes care: a meta-analysis. CMAJ. 2011;183(2):E115-E127.

23. Holman RR, Paul SK, Bethel MA, Matthews DR, Neil HAW. 10-year follow-up of intensive glucose control in type 2 diabetes. $N$ Engl J Med. 2008;359(15):1577-1589.

24. Gaede P, Lund-Andersen H, Parving HH, Pedersen O. Effect of a multifactorial intervention on mortality in type 2 diabetes. $N$ Engl J Med. 2008;358(6):580-591.

25. Kirk JK, D'Agostino RB Jr, Bell RA, et al. Disparities in HbA1c levels between African-American and non-Hispanic white adults with diabetes: a meta-analysis. Diabetes Care. 2006;29(9):2130-2136.

26. Parchman ML, Pugh JA, Romero RL, Bowers KW. Competing demands or clinical inertia: the case of elevated glycosylated hemoglobin. Ann Fam Med. 2007;5(3):196-201.

27. Stange $K$. Is 'clinical inertia' blaming without understanding? are competing demands excuses? Ann Fam Med. 2007;5(4):371-374.

28. Yarnall KSH, Østbye T, Krause KM, Pollak KI, Gradison M, Michener JL. Family physicians as team leaders: "time" to share the care. Prev Chronic Dis 2009;6(2). http://www.cdc.gov/pcd/issues/2009/ apr/08_0023.htm. Accessed Aug 17, 2011] 